\title{
The Effect of Operating of A modified Upflow Anaerobic Sludge Blanket for Landfill Leachate Treatment
}

\author{
Yating $\mathrm{He}^{1}$, Jiaxin Geng ${ }^{2}$, Pengfei $\mathrm{Yu}^{3}$ \\ ${ }^{1}$ Liaoning Beifang Environmental Protection Co., Ltd, Shenyang, 110161, China \\ ${ }^{2}$ Shenyang Municipal Engineering Maintenance Management Office, Shenyang 110055, China; \\ ${ }^{3}$ School of Municipal and Environmental Engineering, Shenyang Jianzhu University, Shenyang, \\ 110168, China;
}

Keywords: Waste leachate, the improved UASB, Hydraulic loading, Volume load.

\begin{abstract}
For its special characteristics of water quality, the biological treatment technology for waste leachate and other special sewage is not yet mature. The study took advantage of the characteristics of the UASB reactor and improved the type of three-phase separator, in order to degrade organic pollutants in landfill leachate better .The results showed that Hydraulic loading was the main process control condition and had more obvious influence on the removal of COD with USAB. Whether hydraulic loading was too big or too small, the removal rate of COD with UASB reactor would decrease. When hydraulic loading is at $0.13 \sim 0.17 \mathrm{~m}^{3} / \mathrm{m}^{2} \cdot \mathrm{h}$, the removal rate of COD would reach the maximum and remain around $70 \%$.Increased hydraulic loading would lead to a large number of accumulation of VFA, and make $\mathrm{pH}$ value decrease in the reactor. When the hydraulic loading increased from $0.11 \mathrm{~m}^{3} / \mathrm{m}^{2} \cdot \mathrm{h}$ to $0.25 \mathrm{~m}^{3} / \mathrm{m}^{2} \cdot \mathrm{h}$, $\mathrm{pH}$ fell to 6.7 and VFAs rose to $0.4 \mathrm{~g} / \mathrm{L}$, the removal rate of COD would be reduced by $20 \%$.
\end{abstract}

\section{Introduction}

At present, the common sewage biological treatment technology has tend to mature, But the biological treatment technology for the industrial waste water, waste leachate and other special sewage is not yet mature ${ }^{[1]}$. Waste leachate contains high concentration of refractory organic pollutants. And it has large fluctuations. Waste leachate mainly comes from from precipitation, surface water and groundwater, portable water by waste, water generated by waste degradation ${ }^{[2]}$. Not only the quantity of waste leachate fluctuates, but the composition and concentration of pollutants might have a large wave with factors such as the composition of waste, landfill environment conditions, fixed number of years of the landfill ${ }^{[3]}$, etc.

Table. 1 Landfill leachate composition and concentration of pollutants in the typical range ${ }^{[4-7]}$

\begin{tabular}{llllll}
\hline Index & Concentration & Index & Concentration & Index & Concentration \\
\hline $\mathrm{pH}$ & $5 \sim 8.6$ & $\mathrm{NO}_{2}{ }^{-}, \mathrm{NO}_{3}{ }^{-}$ & $0.2 \sim 124$ & $\mathrm{Zn}^{2+}$ & $0.2 \sim 370$ \\
$\mathrm{SS}$ & $10 \sim 7000$ & $\mathrm{TP}$ & $0 \sim 125$ & $\mathrm{Cr}$ & $0.01 \sim 8.7$ \\
$\mathrm{COD}$ & $100 \sim 90000$ & $\mathrm{VFA}$ & $10 \sim 1072$ & $\mathrm{Cd}$ & $0.003 \sim 17$ \\
$\mathrm{BOD}_{5}$ & $40 \sim 73000$ & $\mathrm{Cl}$ & $5 \sim 6420$ & E.Coli & $2.3 \times 10^{-} \sim 2.3 \times 10^{8}$ \\
$\mathrm{NH}_{4}{ }^{+}-\mathrm{N}$ & $6 \sim 10000$ & $\mathrm{Mn}^{2+}$ & $0.07 \sim 125$ & & \\
\hline
\end{tabular}

Note: no $\mathrm{pH}$ unit,The basic unit of E.Coli is cfu/L,The basic unit of others is $\mathrm{mg} / \mathrm{L}$

For its special characteristics of water quality, the test takes advantage of the impact of the characteristics of the UASB reactor ${ }^{[8]}$, using the modified UASB reactor process for removing most of organic pollutants in landfill leachate, which is difficult to degrade. We chose the secondary stages three-phase separator, which makes it better to get the gas liquid solid three phase separation. Thus it slows down the problems such as the floating and a lot of loss of sludge because of the leachate special water, and it ensures the efficient and stable operation of the reactor ${ }^{[9]}$.

Compared with the conventional UASB reactor, the interception of sludge ability in this test is stronger. It reduces the runoff of the sludge and ensures the concentration of sludge in the reactor. 
In addition, with the same amount of COD of wastewater treatment, when compared with the traditional aerobic process, the UASB reactor has lots of advantages such as lower processing cost, energy saving, less investment, less energy consumption, lower cost, smaller coverage of an area, etc. What's more, less sludge production reduces the device running costs, and enhances the feasibility of its technology popularization.

\section{Materials and methods}

Experimental set-up. The UASB reactor of this experiment is shown in Fig. 3.1. This apparatus is total 3.5 meters high; the chief UASB reactor is 2 meters high and $100 \mathrm{~mm}$ inside diameter, 200 mm outside diameter. Through adjusting the reactor water temperature control system , water bath temperature is $35{ }^{\circ} \mathrm{C}$.Temperature fluctuation is not more than plus or minus $2{ }^{\circ} \mathrm{C}$. The secondary stages three-phase separator is total 1.5 meters high. The first stage adopts gas collected from the surrounding; secondary adopts gas collected from the middle. The gas generated in the process of reaction is separated and collected. And after desulfurization in water seal bottle, the Volume is measured by wet gas flow meter.

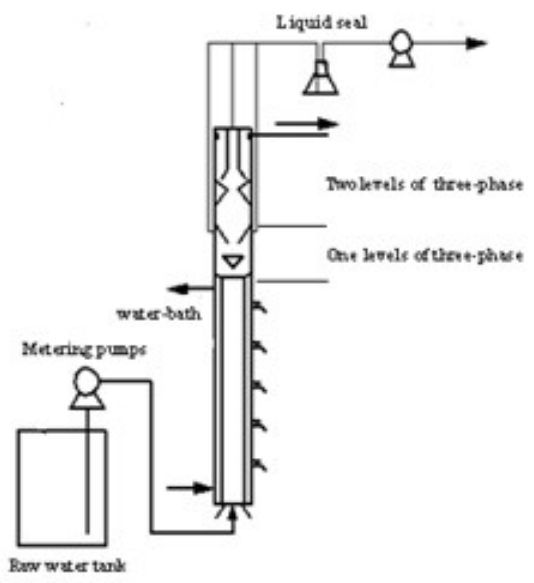

Fig. 1:UASB reactor

Composition of Synthetic Wastewater and Sludge. The garbage leachate in this experiment is from a landfill in Shenyang, the major pollution indicators of garbage leachate is shown in figure (Tab. 2):

Table. 2: Characteristics of the landfill leachate (mg/L, except $\mathrm{pH})$

\begin{tabular}{llllll}
\hline Project & CODcr & BOD $_{5}$ & $\mathrm{NH}_{3}-\mathrm{N}$ & $\mathrm{pH}$ & alkalinity \\
\hline \multirow{2}{*}{ Range } & $15000 \sim$ & \multirow{2}{*}{$5000 \sim 9000$} & $1600 \sim$ & \multirow{2}{*}{$7.6 \sim 8.5$} & $6000 \sim$ \\
& 18000 & & 2200 & & 10000 \\
\hline
\end{tabular}

Activated sludge of aerobic SBR was taken from the second pond backflow sludge of Shenyang northern sewage treatment plant. The sludge concentration is $3000 \mathrm{mg} / \mathrm{L}$. After elutriation and culture for a period of time, the sludge gradually would become a special "mature" activated sludge to adapt to degrade waste leachate. Anaerobic sludge of anaerobic SBR reactor was taken from the anaerobic digester backflow sludge of Shenyang northern sewage treatment plant. After inoculated and cultured for a long time, the modified mesophilic sludge in UASB reactor has formed anaerobic granular sludge which adapts to water quality characteristics of the garbage leachate.

Test Methods a good settling performance of the granular sludge forms. Based on that, the UASB combine the secondary stages three-phase separator system which is installed in the reactor, to get the gas phase, liquid phase and solid phase separation to be more fully.And it is the key for UASB system to degrade COD efficiently. Further, UASB reactor is equipped with an external water bath to maintain a reaction medium temperature of about $35{ }^{\circ} \mathrm{C}$.It is also an important factor for stable operation 
Analysis Method and Instrument The experiment measurement methods are all according to "The water and wastewater monitoring analysis method"(4th edition)(EPA 2002), Specific testing index items and methods are shown in Tab. 3.

Table. 3: Water quality test items and test methods

\begin{tabular}{lll}
\hline Test items & Analysis methods & Measure instruments \\
\hline COD & Rapid sealed digestion method (photometry) & WFJ2100 visible spectrophotometer \\
DO & Portable dissolved oxygen meter method & Electro- thermostatic blast oven \\
pH & Glass electrode method & LODTM-Portable dissolved oxygen meter \\
Temperature & Direct Reading & ZD- 2 meter automatic potentiometric titration \\
VFAs & Gas chromatography. & thermometer \\
\hline
\end{tabular}

\section{Results and Analysis}

\section{The effects of COD influent concentration on COD removal}

Hydraulic loading of UASB inflow water is controlled at $0.133 \mathrm{~m}^{3} / \mathrm{m}^{2} \cdot \mathrm{h}$. COD concentration of inflow water increases from $2000 \mathrm{mg} / \mathrm{L}$ to $10000 \mathrm{mg} / \mathrm{L}$. COD concentration of outflow water is also measured. The results are as follows:

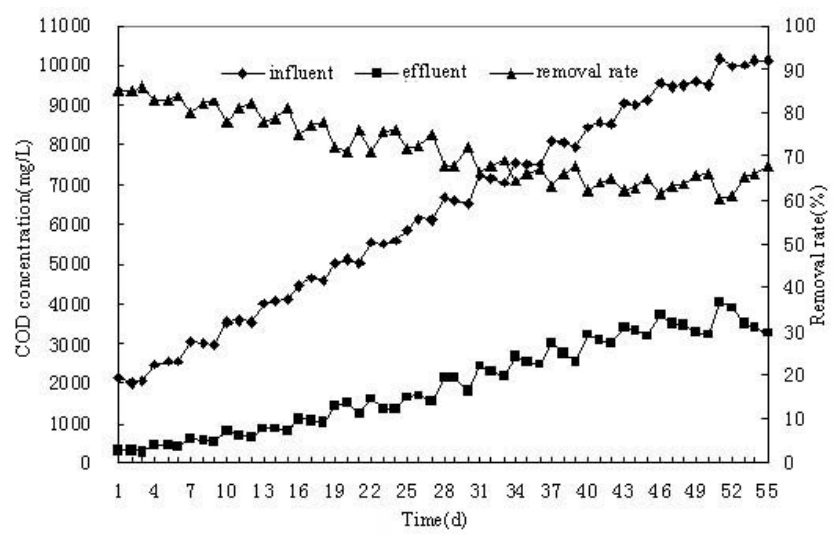

Fig. 2: The COD removal efficiency in UASB at different concentrations influence

According to the Fig. 2, when the hydraulic loading is $0.133 \mathrm{~m}^{3} / \mathrm{m}^{2} \cdot \mathrm{h}$, the removal rate of COD decrease from $85.41 \%$ (at the beginning) down to only $67.72 \%$ (in the last) with the increase of volume load. When the influent COD concentration is stabilized at $9000 \mathrm{mg} / \mathrm{L}$, the treatment effects are slowly rising trend with run time extended and finally stabilized around $70 \%$.It indicates that the sludge landfill leachate began to adapt to the raw water quality.

\section{The effects of Hydraulic loading on COD removal}

The hydraulic loading Of the UASB reactor has a significant impact for anaerobic reaction. The suitable hydraulic loading can not only provide enough nutrients for microorganisms, but also it is conducive to anaerobic microorganism growth. $\mathrm{CH} 4$ and $\mathrm{CO} 2$ which produced in anaerobic process stirs sludge bed in the process of rising, makes the sludge fully contact with nutrients in leachate. Increasing the retention time of leachate in the reactor facilitates the removal of organic matter and decomposition of refractory COD in leachate. Under the condition of suitable flow shear stress, it would contribute to easier formation and growth of anaerobic granular sludge.

The impact of hydraulic retention time on anaerobic UASB reactor treatment is reflected by hydraulic loading. On the one hand, high fluid velocity increases agitation in the inflow water area of the sewage system. It also increases contact between the biological sludge and the inflow organics, improving the removal rate of organic matter. On the other hand, in order to guarantee enough anaerobic sludge in the system, rising velocity should not exceed a certain limit. Within a certain range of hydraulic loading, hydraulic retention time is decided by the reactor height directly.

This test control inflow water COD concentration at $9000 \mathrm{mg} / \mathrm{L}$ around. By adjusting the inflow velocity, the inflow hydraulic loading of UASB is controlled from $0.05 \mathrm{~m}^{3} / \mathrm{m}^{2} \cdot \mathrm{h}$ gradually up to 
$0.27 \mathrm{~m}^{3} / \mathrm{m}^{2} \cdot \mathrm{h}$. Research on the removal efficiency of COD of improved UASB reactor in different hydraulic loading condition. The results are shown in the figures below:

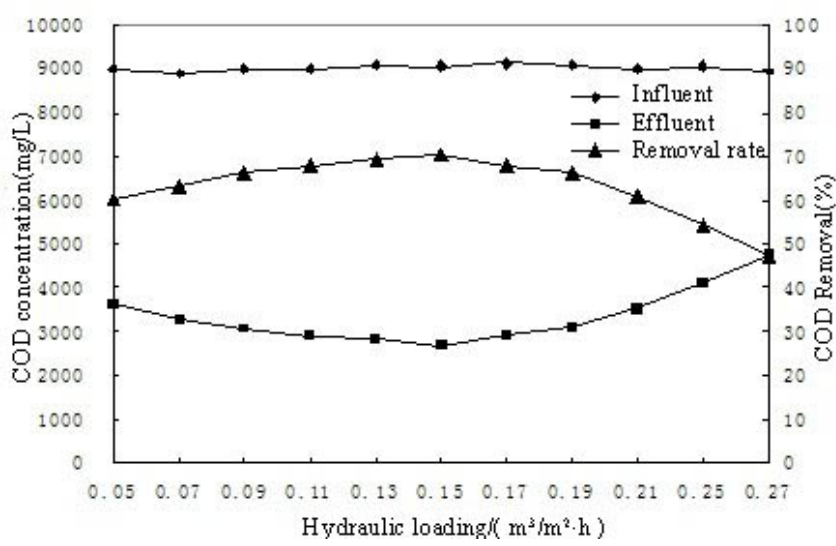

Fig.3: The COD removal efficiency in UASB at different hydraulic loading

Fig. 3 shows that, if hydraulic loading is too big or too small, the removal rate of COD in the UASB reactor will reduce. When hydraulic loading is maintained at $0.13 \sim 0.17 \mathrm{~m}^{3} / \mathrm{m}^{2} \cdot \mathrm{h}$, the removal rate of COD of the UASB reactor will reach the highest, about $70 \%$. The reason may be that when the hydraulic loading in the reactor is too low, nutrients in the reactor will diminish with the decrease of inflow water. When it can't meet the needs of the microbial growth of basic, anaerobic microorganisms can't absorb nutrients from the water. Anaerobic microorganisms can't absorb nutrients from the water. The microorganisms activity decreases, even microorganisms will enter a dormant state. The degradation efficiency of organic matter will reduce. At the same time, because the hydraulic loading in the reactor is too small, round moving of granular sludge and the expansion degree is insufficient, contact of sludge with water is non-uniform. The phenomenon of short flow will occur, causing the granular sludge in the sludge bed reactor can't fully contact with pollutants. But the outflow COD in the UASB will increase at this time.

\section{The effects of Hydraulic loading on $\mathrm{pH}$ and the VFAs}

Correspondingly, when hydraulic loading in the reactor is too high, not only hydraulic retention time is too short and COD is not fully biodegradable, but also the volume load of the reactor may exceed processing limits of the UASB reactor. VFAs accumulate a lot. It makes $\mathrm{pH}$ value and alkalinity decrease in the reactor. And the phenomenon called "acidification” appears at last.

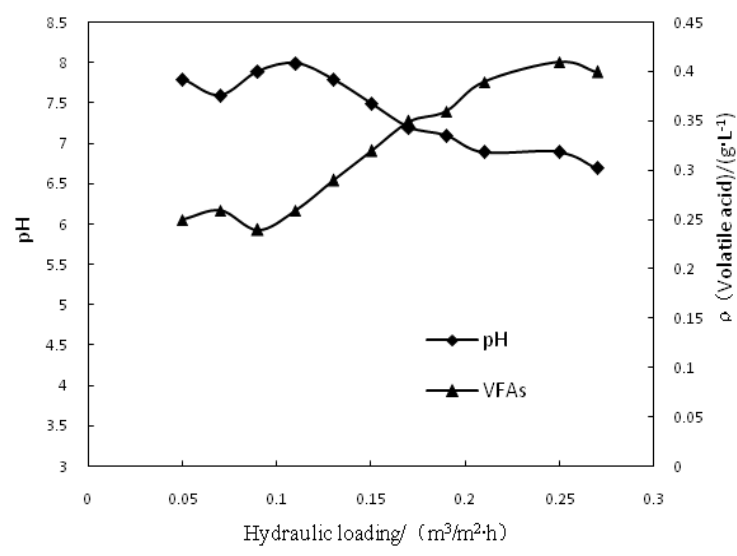

Fig. 4: $\mathrm{pH}$ and VFAs in UASB at different hydraulic loading

As shown in Fig. 4, when the hydraulic loading increased to $0.11 \mathrm{~m}^{3} / \mathrm{m}^{2} \cdot \mathrm{h}, \mathrm{pH}$ began to decline and VFAs began to rise; when the hydraulic loading increased to $0.25 \mathrm{~m}^{3} / \mathrm{m}^{2} \bullet \mathrm{h}, \mathrm{pH}$ drops to 6.7 and VFAs increase to $0.4 \mathrm{~g} / \mathrm{L}$. If measures are not taken right timely, anaerobic microorganisms will dead in a massive number and the reactor could lose treatment effect due to serious acidification. In Fig. 3, in the process where hydraulic loading increases from the $0.13 \mathrm{~m}^{3} / \mathrm{m}^{2} \cdot \mathrm{h}$ to $0.27 \mathrm{~m}^{3} / \mathrm{m}^{2} \cdot \mathrm{h}$, the removal rate of COD was reduced by $20 \%$. Meanwhile, too high volume load will also make the sludge greatly increase gas production and make the sludge bed reactor bloat. Three-phase separator 
cannot get three phase separation timely and effectively, which can lead to a large amount of sludge loss. In addition, the high hydraulic loading and the strong shearing action of flow and air can also cause the destruction and disintegration of the granular sludge.

So, the hydraulic loading of the UASB reactor has a significant impact on anaerobic reaction within the reactor. Appropriate hydraulic loading can not only provide enough nutrients for microorganisms, but also be beneficial to the growth of anaerobic microorganism. $\mathrm{CH}_{4}$ and $\mathrm{CO}_{2}$ produced in anaerobic process will stir the sludge bed in the process of rising, making the sludge fully contact with nutrients in the leachate. Increasing the HRT is beneficial to the removal of COD in the leachate and the degradation of refractory organics. And within the appropriate shear action of flow, it will be more conducive to the formation and growth of anaerobic granular sludge.

\section{The relationship between volume load and hydraulic loading}

When the hydraulic loading is remained at $0.13 \sim 0.17 \mathrm{~m}^{3} / \mathrm{m}^{2} \cdot \mathrm{h}$ and the reactor volume load at 14.1 $\sim 28.8 \mathrm{~kg} / \mathrm{m}^{3} \bullet \mathrm{d}$, the treatment effect will be best. But, when dealing with waste leachate, optimum volume load of ordinary UASB reactor is at commonly $3.6 \sim 19.7 \mathrm{~kg} / \mathrm{m}^{3} \cdot \mathrm{d}$, which is only with single-stage three-phase separator ${ }^{[10]}$. So compared with the conventional UASB reactor in removing waste leachate, the improved UASB has better treatment effect on organic matter and has better loading resistance properties. For sewage of frequent fluctuations in water quality and water flow, like garbage leachate, the reactor can run stably.

Volume load formula:

$\mathrm{q}_{\mathrm{v}}$ - the volume load, $\mathrm{k}_{\mathrm{g}} \mathrm{COD} / \mathrm{m}^{3} \cdot \mathrm{d}$

$$
\mathrm{q}_{\mathrm{v}}=\mathrm{Q} \cdot \mathrm{S}_{0} / \mathrm{V}
$$

$\mathrm{Q}$ — the flow of inflow, $\mathrm{m}^{3} / \mathrm{d}$

$\mathrm{S}_{0}-$ the organic concentration of inflow, $\mathrm{k}_{\mathrm{g}} \mathrm{COD} / \mathrm{m}^{3}$

$\mathrm{V}-$ the effective volume of the UASB reactor, $\mathrm{m}^{3}$

According to the formula (1), volume load of the reactor is influenced by the COD concentration and the water flow.

Hydraulic loading formula:

$\mathrm{q}_{\mathrm{h}}$-hydraulic loading, $\mathrm{m}^{3} / \mathrm{m}^{2} \cdot \mathrm{h}$

$$
\mathrm{q}_{\mathrm{h}}=\mathrm{Q} / \mathrm{S}
$$

$\mathrm{Q}$ — the water flow, $\mathrm{m}^{3} / \mathrm{d}$

$\mathrm{S}$ - effective flow area of UASB reactor,

By the comparison of the above two tests content, it can be seen that when treating waste leachate in UASB system, especially under the condition of low concentration of COD, hydraulic loading is the main process control condition. It is even more important than volume load and has more obvious influence on the removal of COD.

\section{Conclusion}

(1) Whether the hydraulic loading is too large or too small, the efficiency of COD degradation in UASB reactors will reduce. When the hydraulic loading is maintained at $0.13 \sim 0.17 \mathrm{~m}^{3} / \mathrm{m}^{2} \bullet \mathrm{h}$, the removal rate of COD in the UASB reactor will reach the highest at around $70 \%$.

(2) Hydraulic loading is more important than volume load as the main process control condition on treatment of landfill leachate using UASB. And it has more obvious influence on the removal of COD.

(3) Compared with ordinary UASB reactor, the improved UASB reactor is used in the experiment for special water quality such as waste leachate. And it has better treatment effect and better load resistance and can be able to operate stably and efficiently within broader range of volume load.

\section{Acknowledgements}

The paper is supported by Major Science and Technology Program for Water Pollution Control and Treatment of China (2012ZX07212-001) 


\section{References}

[1] Baozhen Wang: Water Pollution Governance: New technology, New concepts, New theories (Science Press, China 2004), p. 11-20.

[2] Li'an Hou: Special Wastewater Treatment Technology and Engineering Examples (Chemical industry press, China 2003), p.62-65.

[3] Kim D J, Lee D I, Jürg Keller: Effect of Temperature and Free Ammonia on Nitrification and Nitrite Accumulation in Landfill Leachate and Analysis of Its Nitrifying Bacterial Community by Fish. Bioresource Technology, Vol. 97 (2006) No.3, p.459-468.

[4] Yaoliang Shen and Baozhen Wang: An Analysis of Chracteristics of Landfill Leachate and Its Variations.Pollution Control Technology, Vol. 12 (1999) No.1, p.10-12.

[5] Xiao Yu, Jiayao Zhang and Chuliang Liu: Pollution Characteristics of Landfill Leachate and Application Trends of Its Treating Technology. Environmental Science and Technology, Vol. 25 (2002) No.5, p. 43-45.

[6] Jun Liu etc: Analyses of organic pollutant components in leachate by combined GC-MS technique.Techniques and Equipment for Environmental Pollution Control, Vol. 4 (2003) No.8, p.32-35.

[7] Jun Yang etc: Treatment Processes and Their Analysis of Municipal Landfill Leachate.Sichuan Environment, Vol. 24 (2005) No.1, p.25-27.

[8] Nanqi Ren, Aijie Wang: Anaerobic biological technology principle and application (Chemical industry press, China 2004), p.57-58.

[9] Xiaodong Huang and Cunduo Zhang: The Main Designing Problems of UASB. Environmental Engineering, Vol. 15 (1997) No.2, p.16-18.

[10]Pohland,F.G.: In Situ Anaerobic Treatment of Leachate in Landfill Bioreactors. Water Science and Technology, Vol. 40 (1999) No.8, p.203-210. 